\title{
Peripartum Blood Transfusions are Associated with Increased Risk of Cancer: A National Retrospective Cohort Study
}

This article was published in the following Dove Press journal:

Clinical Epidemiology

\author{
Geum Joon Cho' \\ Michael S Oh${ }^{2}$ \\ Min-Jeong Oh ${ }^{1}{ }^{1}$ \\ Keon Vin Park ${ }^{3}$ \\ Sung Won $\mathrm{Han}^{3}$ \\ Young Kwang Chae 2,4 \\ 'Department of Obstetrics and \\ Gynecology, Korea University College of \\ Medicine, Seoul, Republic of Korea; \\ ${ }^{2}$ Department of Medicine, Northwestern \\ University Feinberg School of Medicine, \\ Chicago, IL 606 II, USA; ${ }^{3}$ School of \\ Industrial Management Engineering, \\ Korea University, Seoul, Republic of \\ Korea; ${ }^{4}$ Robert H. Lurie Comprehensive \\ Cancer Center of Northwestern \\ University, Chicago, IL 606 II, USA
}

Correspondence: Young Kwang Chae Department of Medicine, Northwestern University Feinberg School of Medicine, 645 N. Michigan Avenue, Suite 1006, Chicago, IL 606II, USA

Tel +I 3/2-926-4248

Email ychae@nm.org
Background: The effect of blood transfusions on the risk of developing primary cancer remains unclear, especially when administered in the peripartum period.

Materials and Methods: We conducted a retrospective cohort study of 270,529 pregnant women who delivered between January 1, 2007 and December 31, 2009, with data obtained from three national databases in South Korea. From this cohort, we identified 4569 patients who received peripartum blood transfusions. We calculated hazard ratios (HRs) for new diagnoses of cancer and adjusted them for relevant clinical factors using a Cox proportional hazards model. Results: During follow-up, patients who received peripartum transfusions had an increased risk of developing cancer, with an adjusted HR of 1.16 (95\% confidence interval [CI], 1.01-1.34). In a subgroup analysis, this risk was significant only among patients who received 3 or more units of blood, with an adjusted HR of 1.40 (95\% CI, 1.10-1.79). Increased risk after transfusions were seen with brain, lung, ovarian, and gallbladder cancers. The difference in cancer risk between the transfusion and no-transfusion groups remained significant during both the first $(1.29 \%$ vs $1.07 \%, \mathrm{p}<0.01)$ and second year $(0.74 \%$ vs $0.56 \%, \mathrm{p}<0.01)$ after delivery.

Conclusion: Receipt of 3 or more blood transfusions in the peripartum period was associated with a significantly increased risk of developing cancer. Prospective studies should be pursued to further understand the link between blood transfusions and long-term oncologic risks.

Keywords: blood transfusion, pregnancy, cancer, immunomodulation

\section{Introduction}

Blood transfusions are an increasingly common indicator of peripartum morbidity. ${ }^{1,2}$ Multiple concerns have been raised regarding the potential long-term risks of blood transfusions, including the possibility of transmitting infectious agents. $^{3,4}$ Transfusions may also modify the immune system via a phenomenon termed transfusion-related immunomodulation (TRIM). ${ }^{5,6}$ According to the TRIM hypothesis, the influx of new antigens and immunologically active mediators during transfusions can contribute to immune tolerance and suppression. ${ }^{7}$ These posttransfusion changes include decreased cytotoxic $\mathrm{T}$ cell and natural killer cell activity and increased secretion of anti-inflammatory cytokines. ${ }^{5,8-10}$

TRIM has been hypothesized to facilitate growth of latent or recurrent cancer by diminishing anti-tumor immune surveillance. ${ }^{7}$ The importance of preserving a robust immunological response to tumors has been highlighted by recent advances in immune checkpoint inhibitors in cancer treatment. ${ }^{11}$ Transfusions may also promote cancer 
development through the transmission of oncogenic viruses, including hepatitis $\mathrm{B}$ and $\mathrm{C}$ viruses, human immunodeficiency virus, and Epstein-Barr virus; however, this risk has markedly diminished in the modern era with screening efforts. ${ }^{12,13}$

Despite these concerns, multiple clinical studies over the past 30 years have yielded contradictory results. Several analyses have demonstrated an association between perioperative blood transfusions and cancer recurrence, ${ }^{10}$ especially in colorectal cancer, ${ }^{14}$ although no causal relationship has been definitively established. ${ }^{14,15}$ There is greater uncertainty in regards to the risk of developing primary malignancies. Most studies have been performed in older patients, who are more likely to have occult cancers that can predispose them to requiring transfusions, ${ }^{16,17}$ or did not control for risk factors such as alcohol and tobacco use. ${ }^{18}$

Pregnancy uniquely represents a situation during which transfusions are commonly indicated in a generally healthy cohort of patients. However, limited data exist on the effect of peripartum transfusions on subsequent cancer risk. We thus tested the hypothesis that blood transfusions in peripartum women would lead to an increased incidence of primary cancers.

\section{Materials and Methods}

\section{Data Sources}

This study was conducted by merging the databases of the Korea National Health Insurance (KNHI) claims, National Health Screening Examination (NHSE), and National Health Screening Program for Infants and Children (NHSP-IC).

In Korea, $97 \%$ of the population is enrolled in the KNHI program, and the KNHI claims database contains all claims information for these individuals. Therefore, nearly all information on patients' diseases and their treatments can be obtained from this centralized database, with the exception of procedures that are not covered by insurance, such as cosmetic surgery. The KNHI database has been extensively validated as a comprehensive populationlevel dataset, including for cancer-related information. ${ }^{19,20}$ Using the KNHI claims database, we identified all pregnant women who delivered between January 1, 2007 and December 31, 2009, and obtained information on blood transfusions in the peripartum period. Subsequent development of cancer was tracked until December 31, 2015.

Enrollees in the KNHI system are invited to undergo a standardized NHSE. The NHSE involves a free, voluntary biennial cardiovascular and age-appropriate cancer screening and is offered to any patient who is employed or above the age of $40 .{ }^{20}$ The pre-pregnancy characteristics of our study population were evaluated via review of the NHSE data. The KNHI system also provides an NHSP-IC for all neonates that includes a health interview with the parents. Information on gestational age at delivery and birth weight was obtained using the NHSP-IC health interview.

This study was approved by the Institutional Review Boards of the Korea University Medical Center.

\section{Study Population}

A flowchart of patient enrollment is shown in Figure 1. Based on the KNHI claims dataset, we identified 666,554 women who had a first delivery between January 1, 2007 and December 31, 2009. To facilitate the evaluation of the prepregnancy characteristics, women were included in the analysis only if they underwent an NHSE within one year prior to their pregnancy. During our study period, $45.6 \%$ of pregnant women participated in the NHSE. In the general population, $66 \%$ of eligible patients participated in the NHSE in $2009 .^{21}$ Among this group, women whose offspring did not participate in the NHSP-IC $(10.3 \%$ of NHSE participants and $5.6 \%$ of full cohort) were excluded from the analysis. Finally, 35,003 women with a prior history of cancer were also excluded.

\section{Outcomes}

Using the KNHI claims dataset, a new diagnosis of cancer was identified by principal or secondary diagnoses based on International Classification of Diseases-10th Revision (ICD-10) codes. Women were classified as having cancer if they were newly diagnosed with cancer (ICD-10 code Cxx.x) between delivery and December 31, 2015. The timing of the initial diagnosis was confirmed by the lack of a medical claim for cancer as a primary or secondary diagnosis before pregnancy.

Pregnancy factors were identified using the KNHI claims dataset, and post-partum hemorrhage (PPH) and preeclampsia were identified according to ICD-10 codes. Based on the KNHI claims dataset, presence of multiple pregnancy, the delivery mode, the use of blood transfusions, and the number of transfusion units administered were confirmed. The peripartum period was defined as time encompassed by the hospitalization during which delivery occurred. All categories of blood product transfusion were included, such as packed red blood cells, pooled platelets, and fresh frozen plasma. Using data on gestational age at delivery from the NHSP-IC, preterm birth was also identified. Preterm birth was defined as a gestational age of $<37$ weeks. 


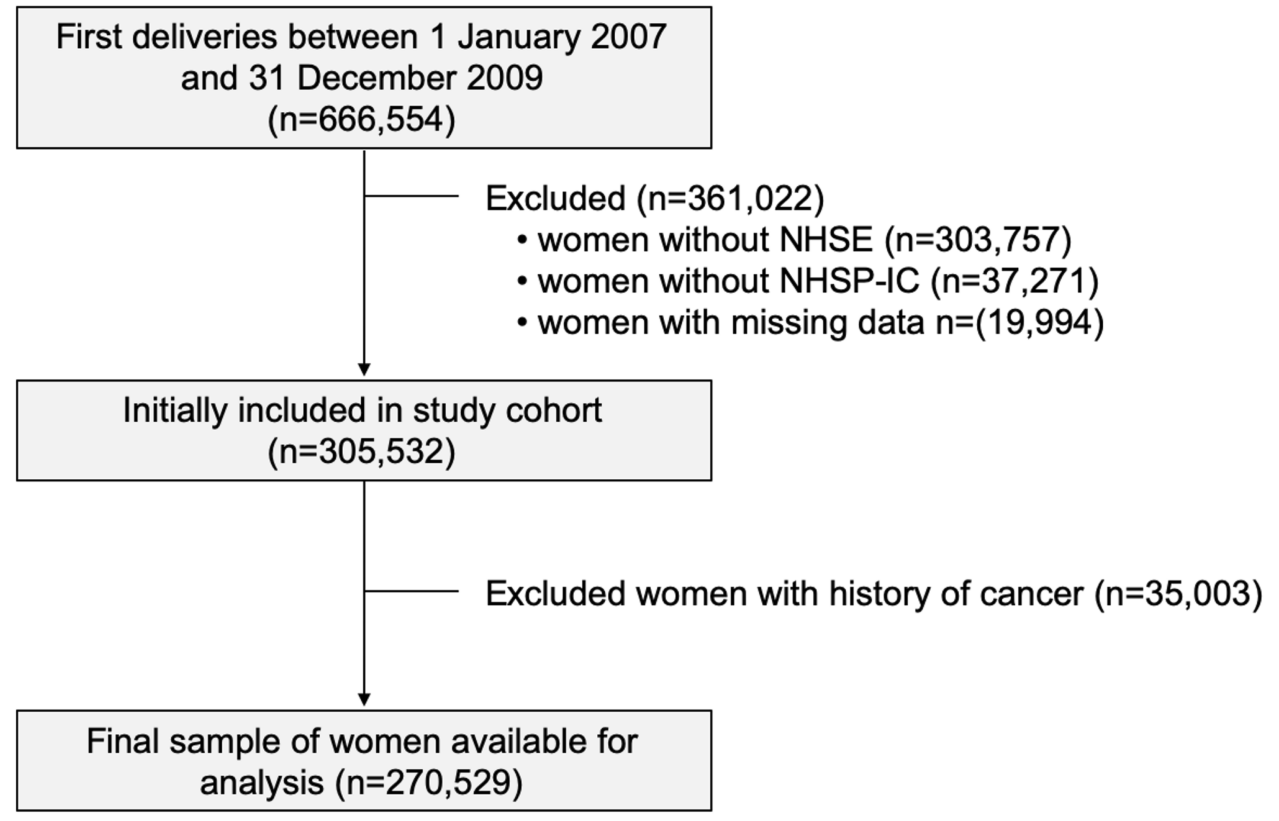

Figure I Flowchart of participant enrollment.

Abbreviation: NHSE, National Health Screening Examination; NHSP-IC, National Health Screening Program for Infants and Children.

Pre-pregnancy factors were evaluated using the NHSE data. Smoking status was identified using health questionnaires. The health examination included the calculation of body mass index (BMI, in $\mathrm{kg} / \mathrm{m} 2$ ). Obesity was defined as BMI $\geq 25 \mathrm{~kg} / \mathrm{m} 2$ according to the cutoffs established by the Korean Society for the Study of Obesity. ${ }^{22}$ Hypertension (HTN) was defined as blood pressure $\geq 140 / 90 \mathrm{mmHg}$ or the current use of antihypertensive medication. Blood samples for laboratory values were obtained after a fast of at least 8 hours. Diabetes mellitus was defined as fasting glucose $\geq 126 \mathrm{mg} / \mathrm{dL}$ or the current use of antidiabetic medication. Abnormal liver function tests were defined as aspartate aminotransferase (AST) $\geq 31$ or alanine aminotransferase (ALT) $\geq 31 \mathrm{mg} / \mathrm{dL}$. High total cholesterol level was defined as levels $\geq 200 \mathrm{mg} / \mathrm{dL}$.

\section{Statistical Analysis}

Continuous and categorical variables are expressed as mean \pm standard deviation (SD) and percentages, respectively. Clinical and biochemical characteristics were compared among groups using the Student's $t$-test for continuous variables and the $\chi^{2}$ test for categorical variables. The cumulative incidence of cancer was estimated using the Kaplan-Meier method and compared using the Log rank test. Cox proportional hazards models were used to estimate the adjusted hazard ratios (HRs) and $95 \%$ confidence intervals (CIs) for the development of cancer. Clinical variables were pre-defined and chosen to reflect both basic health indicators and cancer risk factors. Participants were censored if they developed cancer before or on December 31, 2015 in those without cancer. All tests were two sided, and p-values $<0.05$ were considered statistically significant. Statistical analyses were performed using SAS for Windows, version 9.4 (SAS Inc., Cary, NC, USA).

\section{Results}

Our study cohort included 270,529 women, with 4569 $(1.7 \%)$ of them receiving transfusions. Patients who required transfusions were more likely to be older or to have hypertension, a history of diabetes mellitus, or abnormal liver function tests at baseline. They were also more likely to undergo caesarean section, experience postpartum hemorrhage, develop pre-eclampsia, or have a preterm birth or multiple pregnancy (Table 1).

Women in this cohort were followed for an average of $7.14 \pm 1.59$ years to assess for the development of a cancer diagnosis, with the transfusion group followed for 6.98 \pm 1.75 years and the no-transfusion group followed for $7.14 \pm 1.58$ years. Receipt of perioperative transfusions was associated with a greater likelihood of developing cancer during the study period (HR 1.25, 95\% CI 1.081.44). This association remained significant even after adjusting for multiple clinical variables (HR 1.16, 95\% CI 1.01-1.34). These variables included age, comorbidities (diabetes, hypertension, obesity, abnormal 
Table I Clinical Characteristics of Participants Stratified by Transfusion Status

\begin{tabular}{|c|c|c|c|}
\hline & $\begin{array}{l}\text { No } \\
\text { Transfusion (n } \\
=265,960)\end{array}$ & $\begin{array}{l}\text { Transfusion } \\
(n=4569)\end{array}$ & $P$-value \\
\hline Age (years) & $29.15 \pm 3.04$ & $30.01 \pm 3.54$ & $<0.01$ \\
\hline BMI $\left(\mathrm{kg} / \mathrm{m}^{2}\right)$ & $20.59 \pm 4.21$ & $20.58 \pm 2.62$ & 0.89 \\
\hline Obesity (\%) & $5.83(15,493)$ & $6.26(286)$ & 0.21 \\
\hline Systolic BP (mmHg) & $111.0 \pm 11.11$ & $1111.4 \pm 11.35$ & $<0.01$ \\
\hline Diastolic BP (mmHg) & $69.99 \pm 8.33$ & $70.45 \pm 8.61$ & $<0.01$ \\
\hline HTN (\%) & $4.14(11,021)$ & $5.4 I(247)$ & $<0.01$ \\
\hline Fasting glucose (mg/dL) & $86.15 \pm 13.58$ & $86.62 \pm 20.26$ & 0.12 \\
\hline DM (\%) & $3.21(8,544)$ & $4.73(216)$ & $<0.01$ \\
\hline TC (mg/dL) & $|73.5 \pm 3| .83$ & $173.3 \pm 30.87$ & 0.58 \\
\hline High TC (\%) & $17.03(45,293)$ & $17.33(792)$ & 0.59 \\
\hline AST (mg/dL) & $19.47 \pm 10.78$ & $19.79 \pm 10.21$ & 0.03 \\
\hline ALT (mg/dL) & $|5.2| \pm 16.67$ & $15.63 \pm 14.99$ & 0.06 \\
\hline Abnormal LFT (\%) & $5.76(15,316)$ & $6.94(317)$ & $<0.01$ \\
\hline Smoking (\%) & & & 0.23 \\
\hline Never & $93.56(248,831)$ & $93.13(4255)$ & \\
\hline Ever & $2.89(7685)$ & $2.85(130)$ & \\
\hline Current & 3.55 (9444) & $4.03(184)$ & \\
\hline Multiple pregnancy (\%) & $1.60(4246)$ & $9,81(448)$ & $<0.01$ \\
\hline Cesarean section (\%) & $32.87(87,417)$ & $52.40(2394)$ & $<0.01$ \\
\hline Preterm birth (\%) & $2.96(7862)$ & $|2.4|(567)$ & $<0.01$ \\
\hline Preeclampsia (\%) & $2.19(582 I)$ & $9.46(432)$ & $<0.01$ \\
\hline $\begin{array}{l}\text { Postpartum } \\
\text { hemorrhage (\%) }\end{array}$ & $5.5 \mathrm{I}(14,655)$ & $41.48(1895)$ & $<0.01$ \\
\hline
\end{tabular}

Notes: Values are expressed as mean (SD) or \%. Obesity was defined by BMI $\geq 25 \mathrm{~kg} / \mathrm{m}^{2}$. Abnormal liver function test (LFT) was defined as AST $\geq 31 \mathrm{mg} / \mathrm{dL}$ or $A L T \geq 31 \mathrm{mg} / \mathrm{dL}$.

Abbreviations: BP, blood pressure; HTN, hypertension; DM, diabetes mellitus; TC, total cholesterol; AST, aspartate aminotransferase; ALT, alanine aminotransferase; LFT, liver function tests.

liver function tests, or hypercholesterolemia), smoking status, and obstetric factors (history of multiple pregnancies, caesarean section, preterm birth, or pre-eclampsia).

The relation between transfusions and cancer occurrence was strongly influenced by the number of units of blood product that the patients received (Table 2). There was not a significantly increased risk of developing cancer among patients who received only 1 unit (HR 1.23, 95\% CI $0.91-1.65$ ) or 2 units (HR 1.11, 95\% CI 0.89-138) of blood. However, patients who received 3 or more units of blood had a significantly higher occurrence of cancer (HR 1.51, 95\% CI 1.18-1.93). After adjusting for multiple clinical variables, a similar association was found between cancer and transfusion of 3 or more units of blood (HR $1.40,95 \%$ CI $1.10-1.79$ ).

Further analysis showed that transfusions did not increase the risk for all cancer types (Table 3). Significantly increased
Table 2 Risk of the Development of Cancer According to Transfusion Status

\begin{tabular}{|l|l|l|}
\hline & $\begin{array}{l}\text { Unadjusted HR } \\
\mathbf{( 9 5 \% ~ C l )}\end{array}$ & $\begin{array}{l}\text { Adjusted HR* } \\
\mathbf{( 9 5 \% ~ C l )}\end{array}$ \\
\hline Any transfusion & $1.25(1.08,1.44)$ & $1.16(1.01,1.34)$ \\
I unit $(\mathrm{N}=1072)$ & $1.23(0.91,1.65)$ & $1.13(0.84,1.52)$ \\
2 units $(\mathrm{N}=2196)$ & $1.11(0.89,1.38)$ & $1.04(0.84,1.30)$ \\
$\geq 3$ units $(\mathrm{N}=130 \mathrm{I})$ & $1.51(1.18,1.93)$ & $1.40(1.10,1.79)$ \\
\hline
\end{tabular}

Note: *Adjusted for age, DM, HTN, obesity, abnormal LFT, high total cholesterol, smoking status, multiple pregnancy, cesarean section, preterm birth, and preeclampsia.

risk of occurrence was specifically seen with brain (HR 4.90, 95\% CI 1.93-12.43), lung (HR 4.57, 95\% CI 1.76-11.86), ovarian (HR 2.79, 95\% CI 1.41-5.54), and gallbladder (HR $2.30,95 \%$ CI 1.01-5.26) cancers.

The increased risk of cancer after transfusions was persistent over two years. During the first year after delivery, $1.29 \%$ of patients who received transfusions were diagnosed with cancer, as opposed to $1.07 \%$ of patients who did not receive transfusions $(p<0.01)$. This difference remained significant during the second year, with an incidence of cancer of $0.74 \%$ in the transfusion group and $0.56 \%$ in the no-transfusion group $(p<0.01)$ (Figure 2).

\section{Discussion}

Our data showed that $1.7 \%$ of women required blood transfusions in the peripartum period, which is similar to rates observed in other modern cohorts. ${ }^{23}$ Those patients who received transfusions had a greater incidence of primary cancers in the follow-up period. This effect was only significant among patients who were transfused 3 or more units of blood products.

Prior studies have demonstrated an increased incidence of cancer among patients who received transfusions, but it has been unclear if the transfusions themselves drove this effect. In a large Scandinavian cohort study, the increased rate of new cancers among transfusion recipients was most pronounced in the first 6 months after the transfusion. ${ }^{18}$ The authors thus inferred a reverse causation effect in which patients with subclinical cancer were more likely to require transfusions. Similarly, a case-control study of US patients utilizing Medicare claims data showed that transfusions were only associated with elevated risk of cancer within the first 12 months after transfusion. ${ }^{16}$

By utilizing a dataset limited to peripartum transfusions, we potentially reduced the risk of a reverse causation effect, as the prevalence of predisposing co- 
Table 3 Risk of the Development of Specific Cancer Types Based on Transfusion Status

\begin{tabular}{|c|c|c|c|}
\hline & $\begin{array}{l}\text { No } \\
\text { Transfusion }\end{array}$ & Transfusion & $\begin{array}{l}\text { Adjusted HR* } \\
(95 \% \mathrm{Cl})\end{array}$ \\
\hline Liver & $0.33(882)$ & $0.24(\mathrm{II})$ & $0.7 \mathrm{I}(0.39,1.28)$ \\
\hline Breast & $0.33(873)$ & $0.22(10)$ & $0.57(0.30,1.06)$ \\
\hline Thyroid & I. 12 (2974) & $1.44(66)$ & $1.22(0.95,1.56)$ \\
\hline Gallbladder & $0.05(143)$ & $0.13(6)$ & $2.30(1.01,5.26)$ \\
\hline Brain & $0.02(62)$ & $0.11(5)$ & $4.90(1.93,12.43)$ \\
\hline Uterus & $0.10(27 I)$ & $0.18(8)$ & $1.55(0.76,3.16)$ \\
\hline Colon & $0.80(2 \mid 33)$ & $0.88(40)$ & $1.06(0.77,1.45)$ \\
\hline Lung & $0.02(52)$ & $0.11(5)$ & $4.57(1.76,11.86)$ \\
\hline Stomach & $0.10(272)$ & $0.15(7)$ & $1.45(0.68,3.10)$ \\
\hline Ovary & $0.06(171)$ & $0.20(9)$ & $2.79(\mathrm{I} .4 \mathrm{I}, 5.54)$ \\
\hline Others & $0.25(669)$ & $0.35(16)$ & I.22 $(0.74,2.01)$ \\
\hline
\end{tabular}

Note: *Adjusted for age, DM, HTN, obesity, abnormal LFT, high total cholesterol, smoking status, multiple pregnancy, cesarean section, preterm birth, and preeclampsia.

morbidities and undiagnosed cancers was presumably decreased in this cohort of younger women. We also limited our study population to first deliveries to further limit potential confounders related to prior pregnancies and transfusions. We could find only one comparable study, which evaluated cancer risk after blood transfusion during obstetric delivery in 621 Swedish women. ${ }^{24}$ No association between transfusions and cancer incidence was noted during the 32-year follow-up period, ${ }^{24}$ though this cohort may have been too small to detect any existent effect. It is still possible that residual confounding remained a factor in our study, with subclinical or precancerous lesions leading to increased need for transfusions. However, the increased risk of cancer after blood transfusions remained persistent past the first year, arguing against the possibility that undiagnosed, subclinical cancers were responsible for our result.

A putative mechanism for our observed effect is not clear from our data. Transmission of unscreened carcinogenic agents has been proposed as a potential etiologic factor. ${ }^{17,25}$ Donor seeding of cancer has also been explored as a causative mechanism. This route has been documented most notably in

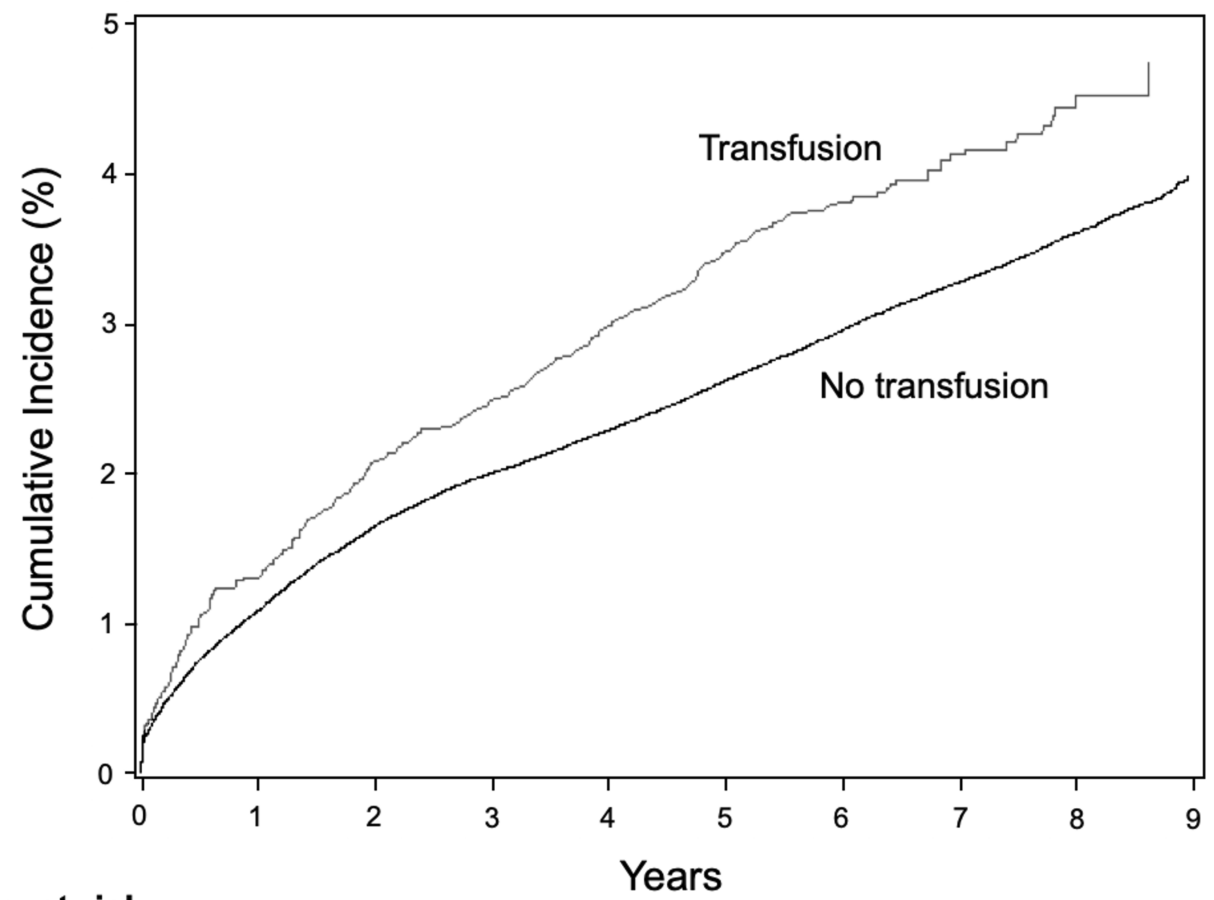

No. at risk

$\begin{array}{lccccccccc}\text { No transfusion } & 259,407 & 256,186 & 254,727 & 253,974 & 253,101 & 252,209 & 162,575 & 78,299 & 419 \\ \text { Transfusion } & 4,409 & 4,343 & 4,316 & 4,294 & 4,272 & 4,257 & 2,603 & 1,255 & 7 \\ \text { No. of cancer } & & & & & & & & & \\ \text { No transfusion } & 2,841 & 4,325 & 5,260 & 5,999 & 6,861 & 7,742 & 8,432 & 8,839 & 8,975 \\ \text { Transfusion } & 59 & 93 & 111 & 133 & 155 & 170 & 181 & 187 & 189\end{array}$

Figure 2 Cumulative incidence of cancer diagnoses. The incidence of cumulative cancer incidence is illustrated for transfusion recipients and non-recipients over a 9-year span. The greater incidence in cancer diagnoses among transfusion recipients remained persistent during this time, suggesting that this difference was not due to occult malignancies that predisposed those patients to requiring transfusions. 
the context of organ transplants, including a case report of two kidney transplant recipients who developed melanoma after receiving organs from a deceased donor who had been successfully treated for melanoma 16 years prior. $^{26}$ However, a large retrospective cohort study did not demonstrate an elevated cancer risk after receiving transfusions from donors with subclinical cancer. ${ }^{27}$ Meanwhile, multiple immunomodulatory effects have been described after blood transfusions. ${ }^{28}$ Preclinical studies have suggested that these effects are mediated by allogeneic leukocytes, leukocyte-derived cytokines, and/or the presence of soluble HLA antigens. ${ }^{5,29}$ These findings demonstrate that transfusions can perturb the immune surveillance and editing process, which is essential to inhibiting carcinogenesis. ${ }^{30}$

Only certain cancers - namely brain, lung, ovarian, and gallbladder cancers - were more common among patients with history of blood transfusions. The difference in lung cancer is notable particularly given the extremely low rates of smoking in this cohort and further supports the importance of immunologic factors in lung cancer. ${ }^{31}$ Alterations in immune function have not been widely discussed as contributing to ovarian carcinogenesis, ${ }^{32}$ which is typically protected against by pregnancy, ${ }^{33}$ but may be worth exploring in light of our results. Previous studies have observed an increased risk for liver cancer after blood transfusions, ${ }^{34,35}$ including one study that noted a persistently elevated risk after 5 years. ${ }^{17}$ Liver cancers were not more common among transfusion recipients in our cohort, which may in part be due to our ability to control for other relevant risk factors. We also note that the above cancers typically grow aggressively. Given our mean follow-up time of about 7 years, it is possible that malignancies known to develop over a longer time course, such as colon cancer, would require longer follow-up before exhibiting any impact from transfusions.

The strengths of our study include the use of a large population-based cohort from a national registry, which allowed for a complete and fully representative dataset. This database also allowed for long-term follow-up of patients and adjustment for many relevant confounding factors. The focus on post-partum patients, who generally represent a young and healthy population, may have further reduced the potential for confounders, such as the presence of occult malignancy. In addition, information on the number of transfusions was unique to our study compared to many similar studies. In studies that did incorporate this variable, several demonstrated a dose-response relationship between number of transfusions and degree of immunomodulation, possibly because a stronger antigen exposure is better able to trigger immunologic changes. ${ }^{36}$ Due to the recency of these data, our findings also reflect modern advances in blood product screening methods and transfusion strategies.

Notable limitations include the retrospective nature of our study and lack of detailed data regarding the transfusions. For example, characteristics of donors were unavailable, specifically in regards to presence of undiagnosed cancer or viral infections at the time of blood donation. Factors that may influence the immunomodulatory effect of transfusions, including storage time ${ }^{37}$ and use of leukocyte-reduced blood, ${ }^{38}$ were not obtained. We note that South Korea does not mandate leukocyte depletion, ${ }^{39}$ and in fact, one study found that only $10.3 \%$ of blood products in South Korea were leukocyte reduced in $2009 .^{40}$ The recency of our data had the disadvantage of limiting the possible follow-up period to 8 years, and any longer-term effects of transfusions were unable to be evaluated. We also note that less than half of women who delivered were ultimately included in the analysis, raising the possibility that this is not a representative subset. The vast majority of patients were excluded due to lack of sufficient NHSE data; it is unclear if this would correlate at all with cancer risk factors.

Finally, our results may be influenced by physiologic factors unique to pregnant women. Pregnancy is known to cause complex immunologic changes that may alter the maternal response to blood transfusions. ${ }^{41,42}$ A recent study, for example, showed that pregnant women may be more likely to have adverse transfusion reactions than nonpregnant women, ${ }^{43}$ possibly due to higher rates of HLA alloimmunization. ${ }^{44}$ It is thus unclear whether our findings relate to pregnancy-specific factors, or if they are generalizable to other patients.

In conclusion, we found that transfusion of 3 or more units of blood in the peripartum period was associated with an increased risk of developing cancer in a comprehensive national cohort. The potential mechanisms for such an effect have not been fully elucidated, though evidence of an immunomodulatory effect has been previously reported. Our results suggest that restrictive strategies for blood transfusions in the obstetric setting should be considered to reduce long-term oncologic risks.

\section{Disclosure}

The authors report no conflicts of interest in this work. 


\section{References}

1. Callaghan WM, Creanga AA, Kuklina EV. Severe maternal morbidity among delivery and postpartum hospitalizations in the United States. Obstet Gynecol. 2012;120(5):1029-1036. doi:10.1097/AOG.0b013e $31826 \mathrm{~d} 60 \mathrm{c} 5$

2. Callaghan WM, Kuklina EV, Berg CJ. Trends in postpartum hemorrhage: United States, 1994-2006. Am J Obstet Gynecol. 2010;202 (4):353e1-6. doi:10.1016/j.ajog.2010.01.011

3. Vamvakas EC, Blajchman MA. Transfusion-related mortality: the ongoing risks of allogeneic blood transfusion and the available strategies for their prevention. Blood. 2009;113(15):3406-3417. doi:10.1182/blood-2008-10-167643

4. Dwyre DM, Fernando LP, Holland PV. Hepatitis B, hepatitis C and HIV transfusion-transmitted infections in the 21st century. Vox Sang. 2011;100(1):92-98. doi:10.1111/j.1423-0410.2010.01426.x

5. Vamvakas EC, Blajchman MA. Transfusion-related immunomodulation (TRIM): an update. Blood Rev. 2007;21(6):327-348. doi:10.1016/j. blre.2007.07.003

6. Brand A. Immunological aspects of blood transfusions. Transpl Immunol. 2002;10(2-3):183-190. doi:10.1016/S0966-3274(02)00064-3

7. Cata JP, Wang H, Gottumukkala V, Reuben J, Sessler DI. Inflammatory response, immunosuppression, and cancer recurrence after perioperative blood transfusions. Br $J$ Anaesth. 2013;110 (5):690-701. doi:10.1093/bja/aet068

8. Kirkley SA, Cowles J, Pellegrini VD, Harris CM, Boyd AD, Blumberg N. Blood transfusion and total joint replacement surgery: T helper 2 (TH2) cytokine secretion and clinical outcome. Transfus Med. 1998;8(3):195-204. doi:10.1046/j.1365-3148.1998.00149.x

9. Innerhofer P, Luz G, Spotl L, et al. Immunologic changes after transfusion of autologous or allogeneic buffy coat-poor versus white cell-reduced blood to patients undergoing arthroplasty. I. Proliferative T-cell responses and the balance of helper and suppressor T cells. Transfusion. 1999;39(10):1089-1096. doi:10.1046/ j.1537-2995.1999.39101089.x

10. Landers DF, Hill GE, Wong KC, Fox IJ. Blood transfusion-induced immunomodulation. Anesth Analg. 1996;82(1):187-204. doi:10.1097/ 00000539-199601000-00035

11. Pardoll DM. The blockade of immune checkpoints in cancer immunotherapy. Nat Rev Cancer. 2012;12(4):252-264. doi:10.1038/ nrc3239

12. Buddeberg F, Schimmer BB, Spahn DR. Transfusion-transmissible infections and transfusion-related immunomodulation. Best Pract Res Clin Anaesthesiol. 2008;22(3):503-517. doi:10.1016/j.bpa.2008.05.003

13. Schreiber GB, Busch MP, Kleinman SH, Korelitz JJ. The risk of transfusion-transmitted viral infections. The retrovirus epidemiology donor study. N Engl J Med. 1996;334(26):1685-1690. doi:10.1056/ NEJM199606273342601

14. Amato A, Pescatori M. Perioperative blood transfusions for the recurrence of colorectal cancer. Cochrane Database Syst Rev. 2006; 1:CD005033.

15. Busch OR, Hop WC, Marquet RL, Jeekel J. Blood transfusions and local tumor recurrence in colorectal cancer. Evidence of a noncausal relationship. Ann Surg. 1994;220(6):791-797. doi:10.1097/ 00000658-199412000-00013

16. Riedl R, Engels EA, Warren JL, Berghold A, Ricker W, Pfeiffer RM. Blood transfusions and the subsequent risk of cancers in the United States elderly. Transfusion. 2013;53(10):2198-2206. doi:10.1111/trf.12071

17. Yang TO, Cairns BJ, Reeves GK, Green J, Beral V. Million women study c. Cancer risk among 21 st century blood transfusion recipients. Ann Oncol. 2017;28(2):393-399. doi:10.1093/annonc/mdw555

18. Hjalgrim H, Edgren G, Rostgaard K, et al. Cancer incidence in blood transfusion recipients. J Natl Cancer Inst. 2007;99(24):1864-1874. doi:10.1093/jnci/djm248
19. Song SO, Jung CH, Song YD, et al. Background and data configuration process of a nationwide population-based study using the korean national health insurance system. Diabetes Metab J. 2014;38 (5):395-403. doi:10.4093/dmj.2014.38.5.395

20. Shin DW, Cho B, Guallar E. Korean national health insurance database. JAMA Intern Med. 2016;176(1):138. doi:10.1001/ jamainternmed.2015.7110

21. Kim H, Lee S, Lim W. Knowing is not half the battle: impacts of the national health screening program in Korea. IZA Discuss Pap. $2017 ; 10650$.

22. Kim MK, Lee WY, Kang JH, et al. 2014 clinical practice guidelines for overweight and obesity in Korea. Endocrinol Metab. 2014;29 (4):405-409. doi:10.3803/EnM.2014.29.4.405

23. Patterson JA, Roberts CL, Bowen JR, et al. Blood transfusion during pregnancy, birth, and the postnatal period. Obstet Gynecol. 2014;123 (1):126-133. doi:10.1097/AOG.0000000000000054

24. Skanberg J, Frisk B. Blood transfusion does not influence the development of malignant tumours. Eur J Surg. 1999;165(6):528-534. doi:10.1080/110241599750006406

25. Reshetnyak VI, Karlovich TI, Ilchenko LU. Hepatitis G virus. World $J$ Gastroenterol. 2008;14(30):4725. doi:10.3748/wjg.14.4725

26. MacKie RM, Reid R, Junor B. Fatal melanoma transferred in a donated kidney 16 years after melanoma surgery. $N$ Engl $\mathrm{J}$ Med. 2003;348(6):567-568. doi:10.1056/NEJM200302063480620

27. Edgren G, Hjalgrim H, Reilly M, et al. Risk of cancer after blood transfusion from donors with subclinical cancer: a retrospective cohort study. Lancet. 2007;369(9574):1724-1730. doi:10.1016/ S0140-6736(07)60779-X

28. Blumberg N, Heal JM. Immunomodulation by blood transfusion: an evolving scientific and clinical challenge. Am J Med. 1996;101 (3):299-308. doi:10.1016/S0002-9343(96)00124-6

29. Brunson ME, Alexander JW. Mechanisms of transfusion-induced immunosuppression. Transfusion. 1990;30(7):651-658. doi:10.1046/ j.1537-2995.1990.30790385527.x

30. Schreiber RD, Old LJ, Smyth MJ. Cancer immunoediting: integrating immunity's roles in cancer suppression and promotion. Science. 2011;331(6024):1565-1570. doi:10.1126/science.1203486

31. Rizvi NA, Hellmann MD, Snyder A, et al. Cancer immunology. Mutational landscape determines sensitivity to PD-1 blockade in non-small cell lung cancer. Science. 2015;348(6230):124-128. doi:10.1126/science.aaa1348

32. Whittemore AS, Harris R, Itnyre J, Halpern J. Characteristics relating to ovarian cancer risk: collaborative analysis of 12 US case-control studies. Am J Epidemiol. 1992;136(10):1175-1183. doi:10.1093/ oxfordjournals.aje.a116426

33. Ness RB, Grisso JA, Cottreau C, et al. Factors related to inflammation of the ovarian epithelium and risk of ovarian cancer. Epidemiology. 2000;11 (2):111-117. doi:10.1097/00001648-200003000-00006

34. Castillo JJ, Dalia S, Pascual SK. Association between red blood cell transfusions and development of non-Hodgkin lymphoma: a meta-analysis of observational studies. Blood. 2010;116 (16):2897-2907. doi:10.1182/blood-2010-03-276683

35. Chang CM, Quinlan SC, Warren JL, Engels EA. Blood transfusions and the subsequent risk of hematologic malignancies. Transfusion. 2010;50(10):2249-2257. doi:10.1111/j.1537-2995.2010.02692.x

36. Refaai MA, Blumberg N. Transfusion immunomodulation from a clinical perspective: an update. Expert Rev Hematol. 2013;6 (6):653-663. doi:10.1586/17474086.2013.850026

37. Grimshaw K, Sahler J, Spinelli SL, Phipps RP, Blumberg N. New frontiers in transfusion biology: identification and significance of mediators of morbidity and mortality in stored red blood cells. Transfusion. 2011;51(4):874-880. doi:10.1111/j.1537-2995.2011.03095.x

38. Jensen LS, Kissmeyer-Nielsen P, Wolff B, Qvist N. Randomised comparison of leucocyte-depleted versus buffy-coat-poor blood transfusion and complications after colorectal surgery. Lancet. 1996;348 (9031):841-845. doi:10.1016/S0140-6736(96)06168-5 
39. Koo BN, Kwon MA, Kim SH, et al. Korean clinical practice guideline for perioperative red blood cell transfusion from Korean society of anesthesiologists. Korean J Anesthesiol. 2019;72(2):91-118. doi:10.4097/ kja.d.18.00322

40. Choi SJ, Kim S, Kim HO, Kwon JR, Lee SW, Shin Y. The status of use of leukoreduced blood products in Korean hospitals. Lab Med Online. 2012;2(4):204-208. doi:10.3343/lmo.2012.2.4.204

41. Mor G, Aldo P, Alvero AB. The unique immunological and microbial aspects of pregnancy. Nat Rev Immunol. 2017;17(8):469-482. doi: $10.1038 /$ nri.2017.64
42. Lee AI, Kaufman RM. Transfusion medicine and the pregnant patient. Hematol Oncol Clin North Am. 2011;25(2):393-413, ix. doi:10.1016/j.hoc.2011.02.002

43. Thurn L, Wikman A, Westgren M, Lindqvist PG. Incidence and risk factors of transfusion reactions in postpartum blood transfusions. Blood $A d v$. 2019;3(15):2298-2306. doi:10.1182/bloodadvances.2019000074

44. Triulzi DJ, Kleinman S, Kakaiya RM, et al. The effect of previous pregnancy and transfusion on HLA alloimmunization in blood donors: implications for a transfusion-related acute lung injury risk reduction strategy. Transfusion. 2009;49(9):1825-1835. doi:10.1111/j.1537-2995.2009.02206.x

\section{Publish your work in this journal}

Clinical Epidemiology is an international, peer-reviewed, open access, online journal focusing on disease and drug epidemiology, identification of risk factors and screening procedures to develop optimal preventative initiatives and programs. Specific topics include: diagnosis, prognosis, treatment, screening, prevention, risk factor modification,

Submit your manuscript here: https://www.dovepress.com/clinical-epidemiology-journal systematic reviews, risk \& safety of medical interventions, epidemiology \& biostatistical methods, and evaluation of guidelines, translational medicine, health policies \& economic evaluations. The manuscript management system is completely online and includes a very quick and fair peer-review system, which is all easy to use. 